\title{
Peran Politik terhadap Pengembangan dan Implementasi Kurikulum
}

\author{
Septriyan Anugrah ${ }^{1}$, Nizwardi Jalinus ${ }^{2}$, Rijal Abdullah ${ }^{3}$, Mudjiran $^{4}$, Rayendra $^{5}$, Diah \\ Anggraini Austin ${ }^{6}$ \\ 1,2,3,4,5 Universitas Negeri Padang, ${ }^{6}$ Universitas Andalas \\ *e-mail: Septriyan@fip.unp.ac.id
}

\begin{abstract}
Efforts to improve the quality of education continue to be carried out by the government, one form of this effort is the development and review of the curriculum so that it is under the times. Several factors underlie curriculum development, including philosophical, psychological, socio-cultural, political, state development and world development, and science and technology (IPTEK) foundations. The process of changing the curriculum in various countries cannot be adapted to the political conditions in that country, therefore the educational curriculum may change at any time according to the political conditions that affect the country concerned. This study aims to analyze and describe the influence of politics on curriculum development in the National Education System. This research is qualitative research using a literature study approach. Furthermore, data were collected through document study.
\end{abstract}

Keywords: politic; development; implementation; curiculum

How to cite : Anugrah, S., Jalinus, N., Abdullah, R., Mudjiran, M., Austin, D., \& Rayendra, R. (2021). Peran Politik terhadap Pengembangan dan Implementasi Kurikulum. Pedagogi: Jurnal Ilmu Pendidikan, 21(2), 139-143. https://doi.org/https://doi.org/10.24036/pedagogi.v21i2.1135

\section{PENDAHULUAN}

Kurikulum memiliki makna yang lebih luas, tidak hanya berupa pengaturan mata pelajaran saja. Hal ini dapat dicermati dalam (Undang-Undang Nomor 20 Tahun 2003 tentang Sistem Pendidikan Nasional) menyatakan bahwa: "Kurikulum adalah seperangkat rencana dan pengaturan mengenai tujuan, isi, dan bahan pelajaran serta cara yang digunakan sebagai pedoman penyelenggaraan pembelajaran untuk mencapai tujuan pendidikan tertentu". Dengan demikian pengembangan dan implementasi kurikulum banyak faktor yang berperan dalam proses tersebut, salah satunya adalah faktor politik negara yang bersangkutan. Berganti pimpinan seringkali berubah pula kebijakan-kebijakan yang diambil dengan maksud untuk mencapai kesempurnaan dari kurikulum yang sudah ada, dan mengikuti tuntutan zaman. Perubahan demi perubahan dilakukan oleh para pengambil keputusan, namun kemungkinan akan menimbulkan konsekuensi yang tidak konsisten, misalnya dari SMA menjadi SMU, kemudian sekolah-sekolah kejuruan yang tadinya STM dan SMEA sekarang di ubah menjadi SMK, dan akhir-akhir ini dari SMU kembali lagi menjadi SMA.

Suatu komponen terpenting dalam pendidikan yaitu kurikulum dan kurikulum dapat menjadi media sosialisasi politik (Made, 2011). Kurikulum di suatu lembaga pendidikan memiliki tiga sumber utama yaitu: (1) pendapat kelompok profesional pendidikan yang seringkali merefleksikan atau mengadaptasi ide dari individu-individu yang didewa-dewakan, seperti John Dewey, John 
Lock, William Stern dan sebagainya; (2) kebutuhan akan dana atau anggaran; dan (3) kelompokkelompok yang berpengaruh di negara itu (Hidayat, 2013). Hal ini sarat dengan nuansa politik dari pengambil keputusan, mereka ingin berinovasi sesuai dengan persepsinya tentang mutu pendidikan atau bagaimana pendidikan yang berkualitas.

\section{METODE}

Penelitian ini menggunakan metode studi literature dengan langkah-langkah sebagai berikut: membaca berbagai litaratur yang relevan (buku, Jurnal, hasil penelitian, dsb,) setelah dilakukan seleksi di dapatkan 25 litaratur yang relevan mengenai pengaruh dan peran politik terhadap kurikulum kemudian dilakukan pencatatan hasil bacaan, mengolah hasil bacaan, dan menganalisa dan mengaitkan dengan permasalahan pelitian. Dalam menganalisa data yang diperoleh selanjutnya dilakukan : editing berkaitan dengan kelengkapan data,dan keselarasan makna; organizing yaitu mengorganisir data yang diperoleh dengan kerangka penelitian yang sudah dirumuskann; dan finding yaitu melakukan analisis data yang diperoleh sesuai dengan teori dan metode yang relevan. Data kualitatif yang telah di analisisi selanjutnya diolah untuk mendapatkan suatu kesimpulan.

\section{TEORI DAN PEMBAHASAN}

Pelaksanaan pendidikan di suatu Negara tidak dapat dilepaskan dengan arah atau kebijakan politik dari Negara yang bersangkutan. Hal ini senada dengan pendapat Wales, dkk. (2016) menyatakan bahwa penerapan politik dapat membantu meningkatkan kualitas pendidikan. Peran pemerintah sebagai Lembaga tertinggi negara yang mengeluarakan kebijakan akan menentukan arah kurikulum sesuai dengan tujuan pengembangan sumber daya manusia yang di inginkan suatu bangsa. Oleh karena itu kurikulum akan berjalan menjadi suatu kebijakan apabila mendapat dukungan secara politik.

Hingga saat ini pemerintah telah menerapkan tujuh bentuk kurikulum, yaitu Kurikulum 1968, Kurikulum 1975, kurikulum1984, Kurikulum 1994, Kurikulum 2004 atau Kurikulum Berbasis Kompetensi, Kurikulum Tingkat Satuan Pendidikan (KTSP), dan yang terakhir adalah Kurikulum 2013. Perubahan kurikulum yang terlalu cepat dapat menimbulkan dampak negatifnya yaitu mutu pendidikan menurun. Hal ini sejalan dengan penelitian dari Maryanto, dkk. (2017), bahwa politik mempengaruhi revitalisasi kurikulum. Perubahan kurikulum yang begitu cepat menimbulkan masalah-masalah baru seperti menurunya prestasi siswa, hal ini dikarenakan siswa tidak dapat menyesuaikan diri dengan sistem pembelajaran pada kurikulum yang baru. Di samping itu guru juga mengalami kesulitan dimana penguasaan pengetahuan dan keterampilan yang barusaja di kuasai, lalu berubah dengan tuntutan kurikulum baru.

Salah satu faktor yang berperan dalam penegmbangan kurikulum adalah faktor politik, hal ini juga dikemukakan oleh (Spindler, 1987) tantangan yang dihadapi para pendidik, pengembang kurikulum, tidak hanya teoretis dan praktis, tetapi juga politik dan sosial. Selain itu Francis P. (Hunkins \& Ornstein, 1989) menyatakan, "Pengembangan Kurikulum juga merupakan proses politik. Hal ini membutuhkan dan berurusan dengan orang-orang berbagai basis kekuatan dan pandangan tentang apa yang membuat pendidikan menjadi baik". Pengaruh politik dalam pengembangan kurikulum dapat terlihat dari setiap pergantian pimpinan sebuah negara, maka kurikulum pendidikan akan selalu dikaji kembali. Perubahan kurikulum yang ada di berbagai negara tidak pernah lepas dari kondisi politik yang sedang berlaku di negara tersebut. Untuk itu, tidak menutup kemungkinan kurikulum akan berubah sewaktu-waktu sesuai dengan kondisi politik negara pada saat itu.

Faktor politik dalam kurikulum dipandang sebagai bagian dari keseluruhan proses pemerintahan dan melibatkan keputusan tentang konten seperti pengetahuan apa yang harus dimasukkan atau dikeluarkan dari kurikulum (Joseph, 2015). (Connelly, M., Fang He, M., \& Phillion, 2008) mengemukakan bahwa "politik mengatur hampir setiap aspek pendidikan dalam kaitannya dengan apa saja yang disediakan sekolah, bagaimana menyediakannya, kepada siapa, dalam bentuk apa, oleh siapa, dan dengan sumber daya apa". Senada dengan hasil penelitian Sukasni dan Efendy 
yang menyatakan bahwa dampak politik terhadap sistem pendidikan dapat menyebabkan adanya ketidakberesan dalam pelaksanaan sistem pendidikan nasional di Indonesia (Sukasni \& Efendy, 2017).

Adakalanya pengaruh kebijakan pemerintah terhadap pengembangan kurikulum terkadang tidak di imbangi dengan kesiapan dalam pelaksanaanya, hal tersebut berdampak terhadap implementasi kurikulum yang telah di tetapkan. Akibatnya kurikulum tersebut tidak dapat dilaksanakan sesuai dengan yang di harapkan. Beberpa faktor penyebab terjadinya permasalahan tersebut antara lain ketidak siapan pendidik, dukungan sarana prasarana yang tidak memadai, dan kondisi geografis yang tidak sesuai dengan tuntutan kurikulum yang di rencanakan. Banyaknya kendala yang dihadapi dalam pelaksanaan kurikulum tersebut akibatnya para pendidik kembali pada penerapan proses pembelajaran yang lama. Dengan demikian tujuan pengembangan kurikulum tidak tercapai dengan baik.

\section{Pengaruh Politik dalam Pengembangan dan Implementasi Kurikulum Indonesia}

Pengaruh politik dalam pengembangan kurikulum sangat besar dampaknya terhadap substansi kurikulum. Pengaruh tersebut mulai dari tingkat nasional hingga tingkat pengambilan keputusan terendah yaitu tingkat kabupaten/Kota. Hal tersebut senada dengan temuan penelitian sebelumnya yang menyatakan bahwa besar pengaruh politik dalam pengembangan kurikulum dan evaluasi baik dari tingkat makro dan mikro (Nkyabonaki, 2013). Pengaruh politik terhadap kurikulum dalam sistem pendidikan nasional secara aktual adalah adanya penghapusan beberapa mata pelajaran, pengurangan dan penggabungan materi pelajaran dengan tujuan efisiensi dan efektivitas pendidikan (Fadlilah Wening Dwi Hastuti \& Sutama, n.d.). Perubahan politik ternyata sering diikuti dengan adanya perubahan kebijakan-kebijakan dalam pengembangan kurikulum pada sistem pendidikan nasional. Hal ini membuktikan bahwa terdapat pengaruh politik yang cukup kuat dengan sistem pendidikan nasional di Indonesia. Perubahan kurikulum yang sering dilakukan tidak menjamin dapat menjamin menjadikan pendidikan itu berkualitas, meskipun perubahan kurikulum itu sudah disesuaikan dengan tuntutan perubahan zaman. Direktur Jenderal Pendidikan Tinggi (Dirjen Dikti) Kementerian Pendidikan dan Kebudayaan, Nizam, mengingatkan prinsip yang paling penting dalam pengembangan kurikulum yaitu learning outcomes dan berkualitas global. Pada saat implementasi kurikulum faktor kemampuan guru sangat mempengaruhi ketercapaian target yang diharapkan. Implementasi tersebut dipengaruhi oleh kemampuan, komitmen, persespi, dan interpretasi guru-guru terhadap kurikulum tersebut. Menurut (Lundeberg \& Levin, 2003) persepsi dan interpretasi guru terhadap kurikulum berakar pada pengetahuan dan pengalaman guru itu sendiri. Pengetahuan dan pengalaman guru ikut menentukan persepsi mereka apakah terlepas persepsinya itu benar atau salah, persepsi akan mempengaruhi komitment dan perilaku individu yang bersangkutan.

\section{Kearifan lokal}

Di indonesia untuk sekolah sendiri kurikulum telah di atur pada (Undang-Undang Nomor 20 Tahun 2003 tentang Sistem Pendidikan Nasional) tentang Pemerintah Daerah memiliki otonomi dan memberikan kewenangan memiliki hak dan kewajiban untuk mengelola urusan pemerintahan di bidang tertentu termasuk masalah pendidikan. Makna otonomi pendidikan adalah mengembalikan tanggung jawab pendidikan kepada stakeholder, yaitu masyarakat itu sendiri. Dalam otonomi pendidikan, masyarakat secara langsung bertanggung jawab atas keberadaan dan proses pendidikan yang dimiliki (Muhaimin, 2009).

Pemberian wewenang dalam bidang pendidikan kepada pemerintah daerah akan sejalan dengan proses pewarisan budaya, hal tersebut sesuai dengan (Undang-Undang Nomor 20 Tahun 2003 tentang Sistem Pendidikan Nasional) pada Bab 1 Ketentuan Umum pasal 1 ayat 16 menyebutkan bahwa "Pendidikan berbasis masyarakat adalah penyelenggaraan pendidikan berdasarkan kekhasan agama, sosial, budaya, aspirasi, dan potensi masyarakat sebagai perwujudan pendidikan dari, oleh, dan untuk masyarakat. Politik memainkan peran dalam memutuskan apa yang akan diajarkan, bagaimana seharusnya diajarkan, bagaimana siswa harus dinilai, serta 
membiayai seluruh proses pengembangan dan implementasi kurikulum (Marsh \& Wills, 1995). Sebagaimana telah disinggung sebelumnya, bahwa perubahan kurikulum itu pertama-tama dipicu oleh kemauan para pemimpin politik yang kemudian memanfaatkan kewenangannya agar melaksanakan apa yang telah diputuskan oleh para pemimpin politik tersebut. Politik ikut menentukan tujuan pendidikan, menentukan konten, pengalaman belajar, dan strategi evaluasi dalam pendidikan. Materi atau cakupan kurikulum dan interpretasinya, adakalanya dipengaruhi oleh keputusan politik, termasuk sistem ujiannya (dalam menentukan anggaranya).

Kearifan lokal menjadi perhatian dalam pengembangan kurikulum, agar tidak meninggalkan kekhasan atau kehususan suatu daerah. Masalah pembangunan karakter bangsa, jiwa interprenership, serta penanaman nilai relegius, tidak terlepas dari muatan kurikulum, bahkan secara eksplisit menjadi salah satu mata pelajaran yang dikemas dalam bentuk muatan lokal. Permasalahan yang timbul berkaitan dengan pengadaan guru yang akan mengajarnya, biaya penggajian guru karena manambah jumlah guru. Hal ini berdampak pada penyediaan anggaran, dengan alasan efisiensi maka mata pelajaran muatan lokal itu digabungkan dengan mata pelajaran yang relevan. Akibatnya penguasaan materi bagi peserta didik menjadi terbatas, ini tidak terlepas dari masalah politik dalam pengambilan keputusan.

\section{Arah Pendidikan Nasional}

Untuk mewujudkan pendidikan indonesia yang lebih baik pengembangan dan implementasi kurikulum pendidikan hendaknya tidak terlepas dari renstra dan Roadmap pendidikan nasional dalam menyiapkan generasi emas 2045. Kurikulum sebagai program dalam pendidikan harus berlandaskan pada peningkatan mutu Sumber daya manusia sehingga dapat membangun bangsa. Meurut Wilson dan Ernesto (Davis, 1990) Manusia adalah pusat dan tolak ukur segalanya dalam kehidupan. Dapat disimpulkan kemajuan sutu bangsa dapat dilihat dari kemampuan sumber daya Manusia yang ada di dalamnya.

Perubahan serta pengembangan kurikulum juga tidak dapat di hindari. akan tetapi dasar perubahan kurikulum yang di buat tidak merubah arah dan tujuan roadmap pendidikan nasional yang mengacu pada Sustainable Development Goals (SDGs) yang telah di tetapkan. Pengembangan kurikulum yang dilakukan juga harus di sesuaikan dengan prinsip pengembangan kurikulum yaitu: 1) prinsip relevansi, 2) prinsip fleksibilitas, 3) prinsip kontinuitas, 4) praktis, dan 5) efektif (Nana Syaodih Sukmadinata, 2010).

Pengembangan kurikulum dan implementasi kurikulum hendaknya juga dapat merangkul berbagai stakeholder dalam dunia pendidikan agar kurikulum yang telah di kembangkan dapat di implementasikan sesuai tujuan yang telah di tetapkan. Upaya tersebut dapat berupa peningkatan peran serta guru dan pemangku kepentingan lain untuk berpartisipasi aktif dalam memberikan umpan balik pelaksanaan kurikulum. penyiapan guru dan tenaga kependidikan untuk mampu melaksanakan kurikulum secara baik, evaluasi pelaksanaan kurikulum secara ketat, komprehensif dan berkelanjutan, penguatan kerja sama antara guru, kepala sekolah, dan pengawas sekolah untuk mendukung efektivitas pembelajaran. Peran Politik yang diharapkan pada perkembanagan kurikulum adalah menghasilkan kebijakan-kebijakan yang dapat mendukung tujuan dalam memajukan bangsa.

\section{KESIMPULAN}

Berdasarkan hasil analisis dari berbagai dokumen maupun pendapat para pakar pendidikan tersebut, dapat diambil kesimpulan berikut:

1. Pengembangan dan implementasi kurikulum tidak dapat terlepas dari masalah politik, karena banyak aspek yang menjadi pertimbangan politik seperti penentuan muatan (content) kurikulum, efisiensi anggaran, dan penyediaan sumber daya.

2. Penentuan muatan kearifan lokal dan penentuan kebijakan-kebijakan pelaksanaan kurikulum menjadi heterogen sebagai dampak adanya otonomi daerah. Daerah Kabupaten/Kota memiliki kewenangan terbatas untuk mengatur pelaksanaan pendidikan. 
3. Kurikulum pendidikan dapat berubah sawaktu-waktu seirama dengan adanya pergantian pimpinan, karena pimpinan yang baru diangkat oleh pemerintah ingin menunjukkan kemampuannya berinovasi. Dampak perubahan kurikulum yang terlalu sering/cepat menimbulkan kesulitan bagi guru dan peserta didik untuk menyesuaikannya dengan tuntutan kurikulum yang baru itu.

4. Evaluasi dan pengkajian kurikulum yang ada perlu di lakukan agar dapat meninjau sejauhmana capaian tujuan yang sudah di tetapkan sebelumnya, pengembangan kurikulum yang dilakukan harus memiliki landasan dari hasil evaluasi kurikulum sebelumnya, peran politik dalam dunia pendidikan di harapakan dapat membantu menghasilkan kebijakan-kebijakan yang mampu memajukan dan mecapai tujuan bangsa sehingga mampu bersaing secara global.

\section{REFERENSI}

Connelly, M., Fang He, M., \& Phillion, J. (2008). The SAGE Handbook of Curriculum and Instruction. SAGE Publications.Inc.

Davis, K. (1990). Human Behavior at Work: Organizational Behavior. Tata McGraw-Hill Publishing.

Fadlilah Wening Dwi Hastuti, N., \& Sutama, M. P. (n.d.). Politik dan Sistem Pendidikan Nasional: Pengaruh Politik terhadap Implementasi Kurikulum di Indonesia. In Doctoral Dissertation. Universitas Muhammadiyah Surakarta.

Hidayat, S. (2013). Pengembangan Kurikulum Baru. Remaja Rosdakarya.

Hunkins, F. P., \& Ornstein, A. C. (1989). (1989). Curriculum Innovation and Implementation. Education and Urban Society. Education and Urban Society, 22(1), 105-114.

Joseph, S. (2015). Curriculum Politics in Higher Education: What Educators Need to do to Survive. International Journal of Higher Education, 4(3), 14-20.

Lundeberg, M. ., \& Levin, B. . (2003). Prompting the Development of Preservice Teachers "Beliefs Through Cases, Action Research, Problem-Based Learning, and Technology", in JRaths and A McAninch (eds), Teacher Beliefs and Classroom Performance: The Impact of Teacher Education. Information Age Publishing, Greenwich CT, 23-42.

Made, P. (2011). Manajemen Pendidikan Indonesia. Rineka Cipta.

Marsh, C. J., \& Wills, G. (1995). Curriculum: Alternative Approaches, on Going Issues. Prentice Hall.

Muhaimin. (2009). Pengembangan Model Kurikulum Tingkat Satuan Pendidikan (KTSP) pada Sekolah dan Madrasah. Rajawali Press.

Nana Syaodih Sukmadinata. (2010). Metode Penelitian Pendidikan. Remaja Rosdakarya.

Nkyabonaki, J. (2013). The Space of Politics in Tanzania`s Curriculum. Scholarly Journal of Scientific Research and Essay (SJSRE), 2(7), 109-117.

Spindler, G. D. (1987). Educational and Cultural Process, Anthropological Approaches. Waveland Press, Inc.

Sukasni, A., \& Efendy, H. (2017). The Problematic of Education System in Indonesia and Reform Agenda. International Journal of Education, 9(3), 183-199.

Undang-Undang RI Nomor 20 Tahun 2003 tentang Sistem Pendidikan Nasional. 